Article

\title{
Lignin Refinery Using Organosolv Process for Nanoporous Carbon Synthesis
}

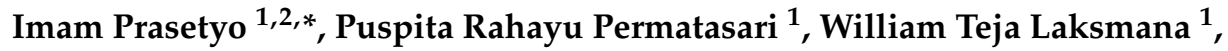 \\ Rochmadi Rochmadi ${ }^{1,2}$, Won-Chun $\mathrm{Oh}^{3}$ and Teguh Ariyanto 1,2,*(D) \\ 1 Department of Chemical Engineering, Faculty of Engineering, Universitas Gadjah Mada Jl. Grafika No. 2 \\ Kampus UGM, Yogyakarta 55281, Indonesia; puspitarahayup@gmail.com (P.R.P.); \\ william.teja.113@gmail.com (W.T.L.); rochmadi@ugm.ac.id (R.R.) \\ 2 The Carbon Material Research Group, Faculty of Engineering, Universitas Gadjah Mada, \\ Yogyakarta 55281, Indonesia \\ 3 Department of Advanced Materials \& Science Engineering, Hanseo University, Chungnam-do 356-706, \\ Korea; wc_oh@hanseo.ac.krn \\ * Correspondence: imampras@ugm.ac.id (I.P.); teguh.ariyanto@ugm.ac.id (T.A.); \\ Tel.: +62-274-649-2171 (I.P. \& T.A.)
}

Academic Editor: Dipendu Saha

Received: 31 May 2020; Accepted: 20 July 2020; Published: 28 July 2020

\begin{abstract}
Porous carbon has been widely used for many applications e.g., adsorbents, catalysts, catalyst supports, energy storage and gas storage due to its outstanding properties. In this paper, characteristics of porous carbon prepared by carbonization of lignin from various biomasses are presented. Various biomasses, i.e., mangosteen peel, corncob and coconut shell, were processed using ethanol as an organosolv solvent. The obtained lignin was characterized using a Fourier transform infrared (FTIR) spectrophotometer and a viscosimeter to investigate the success of extraction and lignin properties. The results showed that high temperature is favorable for the extraction of lignin using the organosolv process. The FTIR spectra show the success of lignin extraction using the organosolv process because of its similarity to the standard lignin spectra. The carbonization process of lignin was performed at 600 and $850^{\circ} \mathrm{C}$ to produce carbon from lignin, as well as to investigate the effect of temperature. A higher pyrolysis temperature will produce a porous carbon with a high specific surface area, but it will lower the yield of the produced carbon. At $850{ }^{\circ} \mathrm{C}$ temperature, the highest surface area up to $974 \mathrm{~m}^{2} / \mathrm{g}$ was achieved.
\end{abstract}

Keywords: carbonization; extraction; organosolv process; porous carbon

\section{Introduction}

Porous carbon is a versatile material with wide applications, for example: in adsorption [1], separation [2], purification [3], gas storage [4], electrochemical storage [5] and catalysis [6] due to the advantageous properties of pore- and microstructures. There are many precursors for porous carbon preparation, for instance: biomass (natural polymer), synthetic polymer and metal carbide. Biomass materials occur in nature, for example: peat, coconut shell and wood. Porous carbons produced from these natural materials are very dependable concerning elemental composition of materials. These are controlled by e.g., plant age, location and management activities of a plantation. For a synthetic polymer we can adjust the pore structure and purity of materials during synthesis of the polymer [7]. Depending on the preparation method of the polymer, a hierarchical pore architecture and a monomodal pore structure (a narrow pore size distribution) can be obtained [8]. It is important to note that a narrow pore size distribution is important, especially for applications where diffusion limitation is desirable. Metal carbide is new variety of carbon precursor from which high purity and a specific 
pore range of porous carbon can be obtained [9]. From three types of porous carbon precursors the biomass material is provided in a large amount and is typically cheap. The biomass can be separated into two major products i.e., cellulose and lignin. Lignin has promise as a carbon precursor since it has a large portion of aromatic hydrocarbons [10] and high content of carbon element [11]. Yet, there are still limited studies of lignin for porous carbon synthesis.

To solubilize lignin, a conventional process like the Soda or Kraft process can be employed. In the Soda process, delignification occurs due to a breakdown of ether (-C-O-C-) bonding in lignocellulose. Lignin is then solubilized in an ionic solution. Solubilized lignin can then be precipitated using acids. However, the Soda process also breaks ether bonding in lignin polymeric structures. This produces fragmented lignin polymeric structures with lower polymeric density. The Kraft process is a modification of the Soda process, which uses the addition of sodium sulfide in a sodium hydroxide solvent [12]. Therefore, these two processes are too harsh to solubilize lignin, producing a dramatic change in polymeric structures of lignin. Ionic liquid and organosolv processes are two examples of processes which can solubilize lignin without affecting its original structure. Ionic liquid works due to interference of inter and intramolecular hydrogen bonding in lignocellulose [13]. Ionic liquids include imidazolium, pyridinium, ammonium cations, etc. Despite being able to extract lignin in a high yield, ionic liquid is very expensive [14]. The organosolv process dissolves lignin by breaking lignocellulose in the ether linkage [15]. It employs solvents like dioxane, ethanol, butanol and ethylene glycol. The organosolv solvent is relatively cheap [16]. Furthermore, some studies show promise in extracting lignin using the method [17].

We described previously the possibility of preparation of porous carbon from mangosteen peel lignin, which was extracted using an organosolv process at $70{ }^{\circ} \mathrm{C}$ [18]. To evaluate the efficacy of the method, it is necessary to expand the study using other lignin sources i.e., corncob and coconut shell, and a higher extraction temperature. This paper presents a comparison of lignin extracted from various biomasses and its use for porous carbon synthesis. To investigate lignin properties and the respective porous carbon produced, characterizations like Fourier transform infrared (FTIR) spectroscopy, scanning electron microscopy (SEM) and $\mathrm{N}_{2}$-sorption analysis were employed. The results demonstrate another approach to producing high quality porous carbon by using lignin as a precursor.

\section{Results and Discussion}

\subsection{Lignin Yield}

Figure 1 shows the yield of lignin extraction from various biomasses using the organosolv process. Mangosteen peel had a higher yield than the others. To study the influence of temperature, the extraction condition was increased $70^{\circ} \mathrm{C}$ to $150{ }^{\circ} \mathrm{C}$. As a representative, mangosteen peel was chosen. When the temperature of the organosolv process was increased from $70{ }^{\circ} \mathrm{C}$ to $150{ }^{\circ} \mathrm{C}$, the yield of extraction of mangosteen peel was higher $(60.63 \%)$. Therefore, increasing temperature can enhance the yield of lignin during organosolv extraction. Ethanol solutions reduce surface tension at high temperatures thereby accelerating diffusion from the breakdown of lignin bonds into organic solutions [19]. As a comparison, all biomasses were also treated using the conventional method of the Soda process (see Figure 1). The solubility of lignin in soda solutions was higher than in organic solutions. The solubility of lignin in a $0.25 \mathrm{M}$ soda solution is $32 \mathrm{~g} / \mathrm{L}$ [20] while the solubility of lignin in $60 \%$ ethanol solution is $16 \mathrm{~g} / \mathrm{L}$ [21]. 


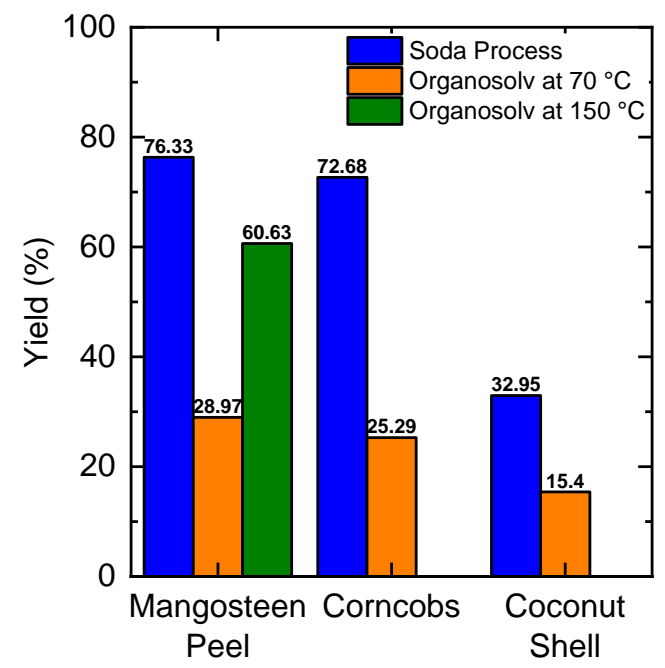

Figure 1. Yield comparison of lignin extracted using organosolv and soda processes. Data of lignin yield of mangosteen peel at $70{ }^{\circ} \mathrm{C}$ taken from our previous study [18].

\subsection{Characteristics of Lignin}

The extraction and isolation processes of lignin have a crucial role in separating lignin from cellulose and hemicellulose without breaking the lignin original molecular structure. The derivations of lignin monomers are $p$-hydroxyphenyl monomers ( $\mathrm{H}$ type), guaiacyl monomers ( $\mathrm{G}$ type), and syringyl monomers (S type) [22]. The lignin obtained from every type of biomass waste was analyzed with FTIR spectroscopy to ensure that the lignin was successfully obtained. The graph was then compared with the standard functional group of lignin.

The lignin functional group from the organosolv extractions of various biomass waste can be seen in Figure 2. Lignin from mangosteen peel, lignin from corncob and lignin from coconut shell, which were extracted using the organosolv process at $70^{\circ} \mathrm{C}$, are labeled as LMP, LCC, and LCS, respectively. Additionally, lignin from mangosteen peel, which was extracted using the organosolv process at a higher temperature of $150^{\circ} \mathrm{C}$, is labeled as LMPT. For the spectra evaluation, several publications studying FTIR characterization of lignin were used [22-25]. At a wavelength of $1600 \mathrm{~cm}^{-1}$, lignin in (a), (b), (c), and (d) showed C=C stretching of the aromatic ring in lignin while in $1510 \mathrm{~cm}^{-1}$ (c) and (d) showed the aromatic skeleton vibrations. $\mathrm{C}-\mathrm{H}$ deformation (asymmetric in $-\mathrm{CH}_{3}$ and $-\mathrm{CH}_{2}$ ) was shown in the $1460 \mathrm{~cm}^{-1}$ wavelength of lignin (b), (c), and (d). At a wavelength of $1422 \mathrm{~cm}^{-1}$, lignin (a), (c), and (d) showed C-H deformation in lignin. C-H stretching of $\mathrm{G}$ units was shown from lignin (a) and (b) in the $1283 \mathrm{~cm}^{-1}$. The peaks in $1162 \mathrm{~cm}^{-1}$ showed by lignin (a), (b), (c), and (d) were typical for $\mathrm{H}, \mathrm{G}$, and $\mathrm{S}$ units of lignin. In $1110 \mathrm{~cm}^{-1}$ peak, lignin (a), (b), (c) and (d) showed aromatic C-H deformation of syringyl units, while in $917 \mathrm{~cm}^{-1}$, lignin (a) and (b) showed C-H bending of the syringyl unit's aromatic ring. The C-H bending of syringyl units was shown in $840 \mathrm{~cm}^{-1}$ of lignin (c) and (d). Peaks observed in FTIR spectra and the functionalities are tabulated in Table 1.

Table 1. Peaks Observed in FTIR Spectra.

\begin{tabular}{ccc}
\hline Sample & Wavenumber $\mathbf{( c m}^{-\mathbf{1}} \mathbf{)}$ & Functionality \\
\hline LMP; LCC; LCS; LMPT & 1600 & C=C stretching of the aromatic ring \\
LCS; LMPT & 1510 & Aromatic skeleton vibrations \\
LCC; LCS; LMPT & 1460 & C-H deformation (asymmetric in $-\mathrm{CH}_{3}$ and $\left.-\mathrm{CH}_{2}-\right)$ \\
LMP; LCS; LMPT & 1422 & C-H deformation in lignin \\
LMP; LMPT & 1283 & C-H stretching of G units \\
LMP; LCC; LCS; LMPT & 1162 & H, G, and S units of lignin \\
LMP; LCC; LCS; LMPT & 1110 & Aromatic C-H deformation of syringyl units \\
LMP; LMPT & 917 & C-H bending of syringyl units, aromatic ring \\
LCS; LMPT & 840 & C-H bending of syringyl units \\
\hline
\end{tabular}




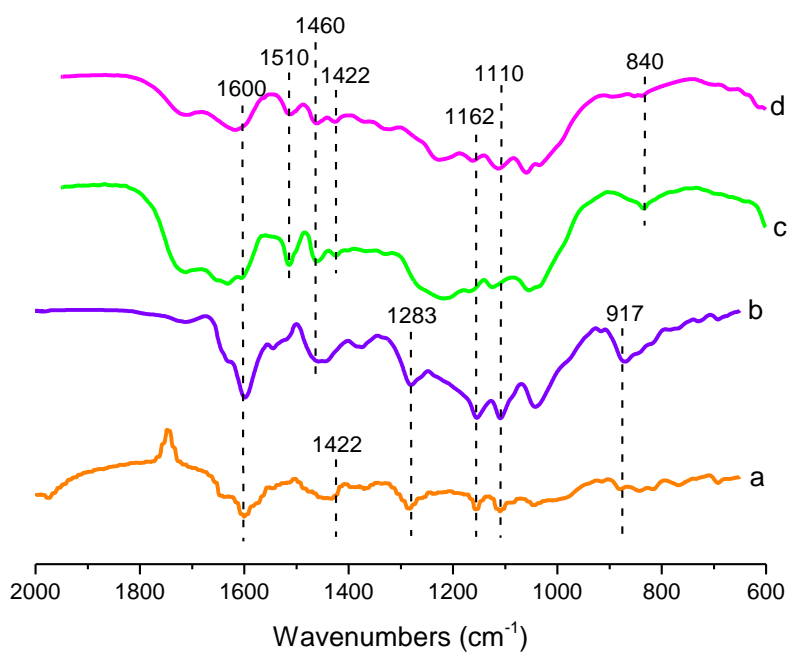

Figure 2. Fourier transform infra-red (FTIR) band from (a) LMP, (b) LCC, (c) LCS, dan (d) LMPT. Y-axis is transmittance.

Figure 2 shows that the lignin from organosolv extraction of various biomass waste had syringyl and guaicyl groups. They are like a typical lignin standard. Meanwhile, the functional group from soda extraction for various biomass waste did not have the group of syringyl and guaicyl but only had the stretching unit in the aromatic group of lignin. This confirms that the organosolv process can extract lignin while saving most of the original structure of lignin.

Lignin molecular weight can be indicated by the viscosity of the lignin solution [26]. Lignin precursors have different fractions of lignin-forming monomers so they can produce different molecular weights. The viscosity was measured by a vapor pressure osmometer with $\mathrm{NaOH} 0.5 \mathrm{~N}$ as a solvent. Table 2 displays the viscosity of lignin solutions.

Table 2. Viscosity of lignin.

\begin{tabular}{ccc}
\hline \multirow{2}{*}{ Lignin Source } & \multicolumn{2}{c}{ Viscosity $(\mathrm{cP})$} \\
\cline { 2 - 3 } & Organosolv Process & Soda Process \\
\hline Mangosteen peel & $1.43 / 1.97\left(\right.$ at $\left.150{ }^{\circ} \mathrm{C}\right)$ & 1.23 \\
Corn cob & 1.63 & 1.17 \\
Coconut shell & 1.53 & 1.20 \\
\hline
\end{tabular}

As can be seen in Table 2, lignin, which was extracted using the organosolv process at $150{ }^{\circ} \mathrm{C}$, features the highest value of viscosity compared to the other lignin sources. It can be an indication that the molecular weight of the mangosteen peel is higher compared to the other lignin sources. With respect to the Soda process, the viscosity of lignin obtained from the organosolv method has a higher value. The low viscosity of lignin obtained from the Soda process suggests that the molecular structure of lignin was fragmented into smaller forms $[27,28]$. Interestingly, using the organosolv extraction process, the structures of the lignin are more or less preserved, as indicated by the high viscosity.

\subsection{Characteristics of Porous Carbon Produced from Lignin}

The precursors used in porous carbon preparation were lignin extracted from mangosteen peel (MP), corncob (CC), and coconut shell (CS). The temperatures used for the carbonization process were $600{ }^{\circ} \mathrm{C}$ and $850^{\circ} \mathrm{C}$. Figure 3 shows that at $600{ }^{\circ} \mathrm{C}$, more carbon products were obtained than at $850{ }^{\circ} \mathrm{C}$ for all of biomass waste precursors. The increase of carbonization temperature resulted in decreasing the product. This was because of a thermal degradation process in the molecular structures of lignin. Lignin extracted using the Soda process was also carbonized at $600{ }^{\circ} \mathrm{C}$. The yield was lower than $10 \%$, 
which is likely due to low thermal degradation of lignin obtained from the Soda process (data not shown, see literature [18]). The carbon produced was labeled in accordance with the type of lignin and carbonization temperature. For instance, LMP-850 means porous carbon produced by pyrolysis of lignin from mangosteen peel at $850{ }^{\circ} \mathrm{C}$.

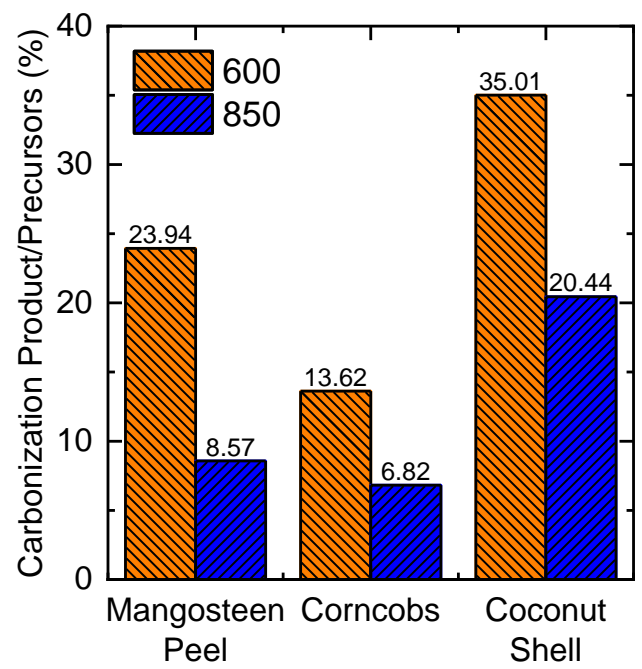

Figure 3. Percentage of product/precursor at carbonization temperatures $600{ }^{\circ} \mathrm{C}$ and $850{ }^{\circ} \mathrm{C}$. Data of carbonization yield of mangosteen peel taken from our previous study [18].

Scanning electron microscopy (SEM) analysis was performed to evaluate the details of the microscopic surface structure of the carbon material. The carbon morphology in Figure 4a shows a rigid and ordered pore structure similar to Figure 4c. The LMPT-850 carbon in Figure 4b shows morphology like a sponge with more voids. The SEM result of LMP-850 in Figure 4D shows flake structures. For the LCC-600 and LCC-850 (Figure 4e,f), these carbons possess rigid flakes. For carbon from coconut shell, the LCS-850 in Figure 4h shows flatter surfaces with many voids compared with LCS-600 in Figure $4 \mathrm{~g}$ Therefore, morphologies of carbon depend on the material precursors and carbonization temperature, which is in agreement with the literature [7]. It is important to note that the morphologies of carbon synthesized by carbonization of lignin (lignin-derived carbon) are very different from the morphologies of porous carbon produced directly from biomass of mangosteen peel [29], corncob [30] and coconut shell [31].
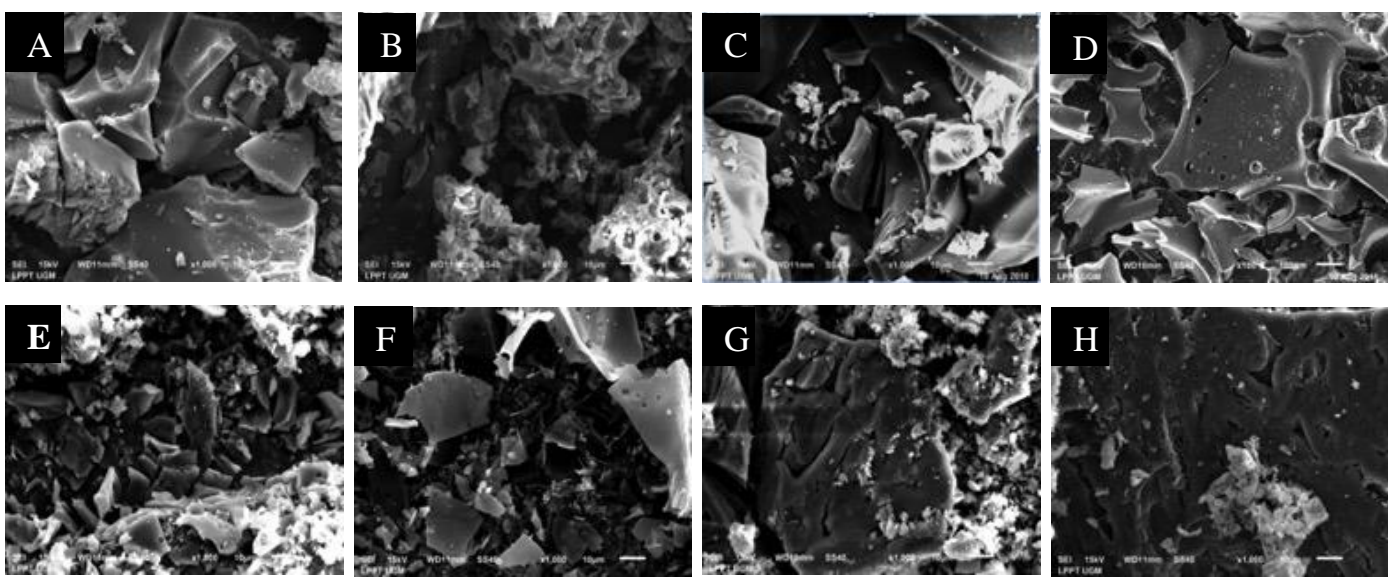

Figure 4. SEM images of carbon fibers: (a) LMPT-600; (b) LMPT-850; (c) LMP-600; (d) LMP-850; (e) LCC-600; (f) LCC-850; (g) LCS-600; (h) LCS-850. Figure (c) and (d) taken from our previous study [18], Copyright AIP Publishing, 2020. 
The carbon materials, from the carbonization process for various precursors and carbonization temperatures were characterized by nitrogen adsorption and desorption. From $\mathrm{N}_{2}$-sorption isotherms, pore structure, pore size distribution and micropore structure were evaluated. The characterization of pore size distribution was used to evaluate the uniformity of pore sizes formed in the carbonization process. The uniformity of pore size can be seen from a narrow pore size distribution. The quenched solid density functional theory (QSDFT) method was used to evaluate the pore size distribution of produced carbon. According to the International Union of Pure and Applied Chemistry (IUPAC), pores with a size of 2-50 $\mathrm{nm}$ are classified as mesoporous while below $2 \mathrm{~nm}$ categorized as micropores [32].

Figure 5A displays the nitrogen adsorption-desorption curves of LMPT for the carbonization temperature of $600^{\circ} \mathrm{C}$ and $850^{\circ} \mathrm{C}$. Both carbons show the isotherm of type IV (IUPAC Classification [32]), where the shape of this isotherm curve type becomes more vertical in the range of relative pressure near 1.0. In the specific range, the desorption line does not coincide with the adsorption line, which is called the hysteresis phenomenon. This phenomenon happens because there is a difference in the contact angle of the gas molecules in the pore when adsorption and desorption happen. Condensation in the capillaries of carbon pores is also another reason for this phenomenon [33].

A

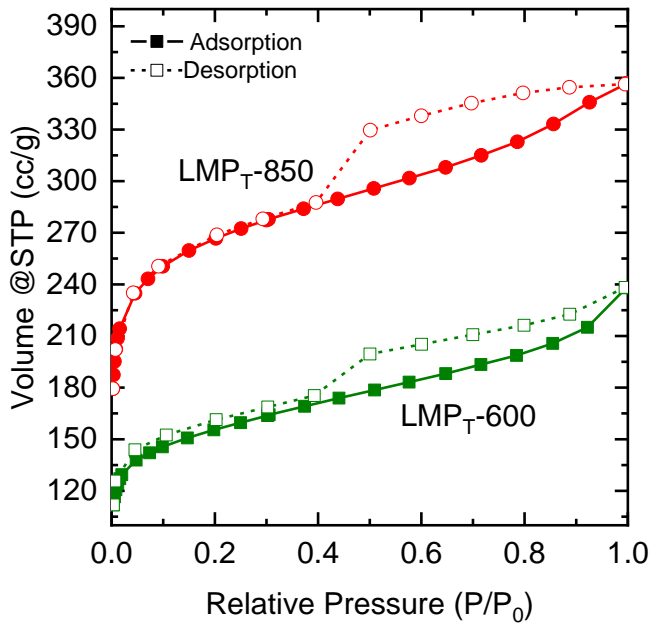

B

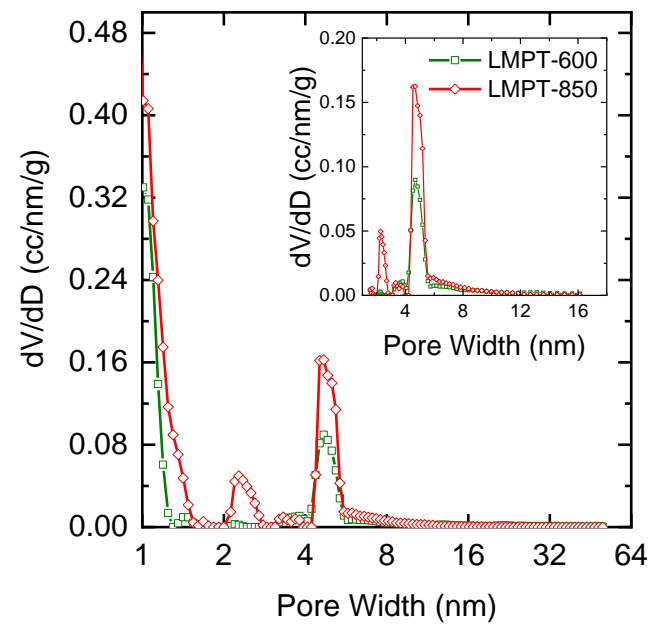

Figure 5. (A) Adsorption and desorption of nitrogen in carbon mangosteen peel lignin extracted using organosolv at $150^{\circ} \mathrm{C} ;($ B) QSDFT-N 2 pore size distribution of carbon mangosteen peel lignin extracted by using organosolv at $150^{\circ} \mathrm{C}$.

Figure $5 \mathrm{~B}$ shows the pore size distribution of mangosteen peel lignin extracted using the organosolv process at $150{ }^{\circ} \mathrm{C}$. Both carbons feature a pore size in the range of $1-50 \mathrm{~nm}$, which is in the micropore and mesopore ranges. The pore size distribution for both carbons is broad and diverse. The majority of pores are in the micropore range as indicated by a high fraction of pores below $2 \mathrm{~nm}$. Interestingly, LMPT-600 also features pores in a mesopore range and a narrow pore size distribution with a peak of ca. $5 \mathrm{~nm}$. This peak becomes more intense in LMPT-850, indicating that more mesopores are produced at a higher carbonization temperature. The presence of mesopore is likely associated with a large amount of decomposition of material [34] and a minor fraction of mineral in the lignin [35].

Figure 6 displays the nitrogen adsorption-desorption curves for carbon produced from lignin of corncob and coconut shell. The LCC-600 in Figure 6A and LCS-600 in Figure 6B show the type II isotherm (IUPAC Classification [32]) while LCC-850 in Figure 6A and LCS-850 in Figure 5B show the type IV isotherm. The change of the isotherm curve is likely caused by effective pore formation during the carbonization process at higher temperature [35].

Figure 7A shows the pore size distribution of LCC at the carbonization temperatures of $600^{\circ} \mathrm{C}$ and $850^{\circ} \mathrm{C}$ while Figure $6 \mathrm{~B}$ displays the pore size distribution of LCS at the carbonization temperatures of $600^{\circ} \mathrm{C}$ and $850^{\circ} \mathrm{C}$. All carbons had a pore size between $1-50 \mathrm{~nm}$, which is in the range of micropores and mesopores, where all the carbons had multimodal or broad pore size distribution. 

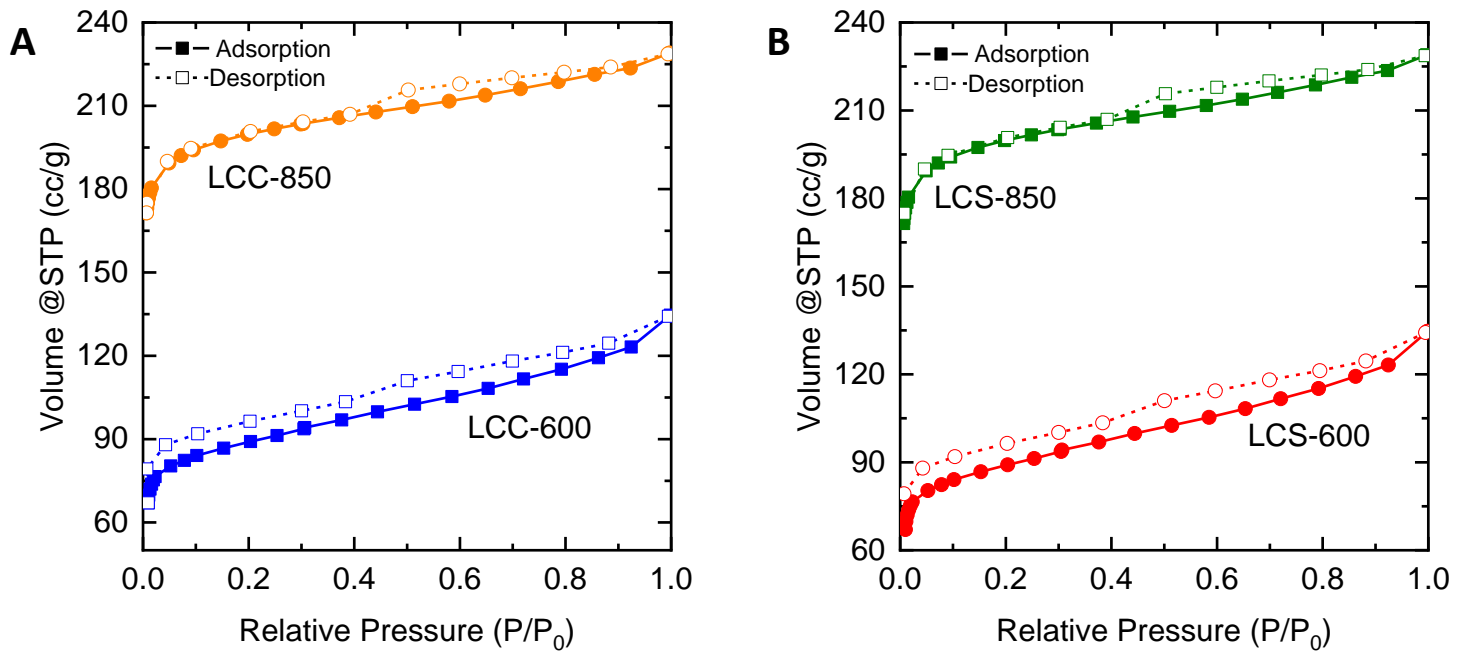

Figure 6. Adsorption and desorption of nitrogen in carbon (A) corncob lignin; (B) coconut shell lignin.
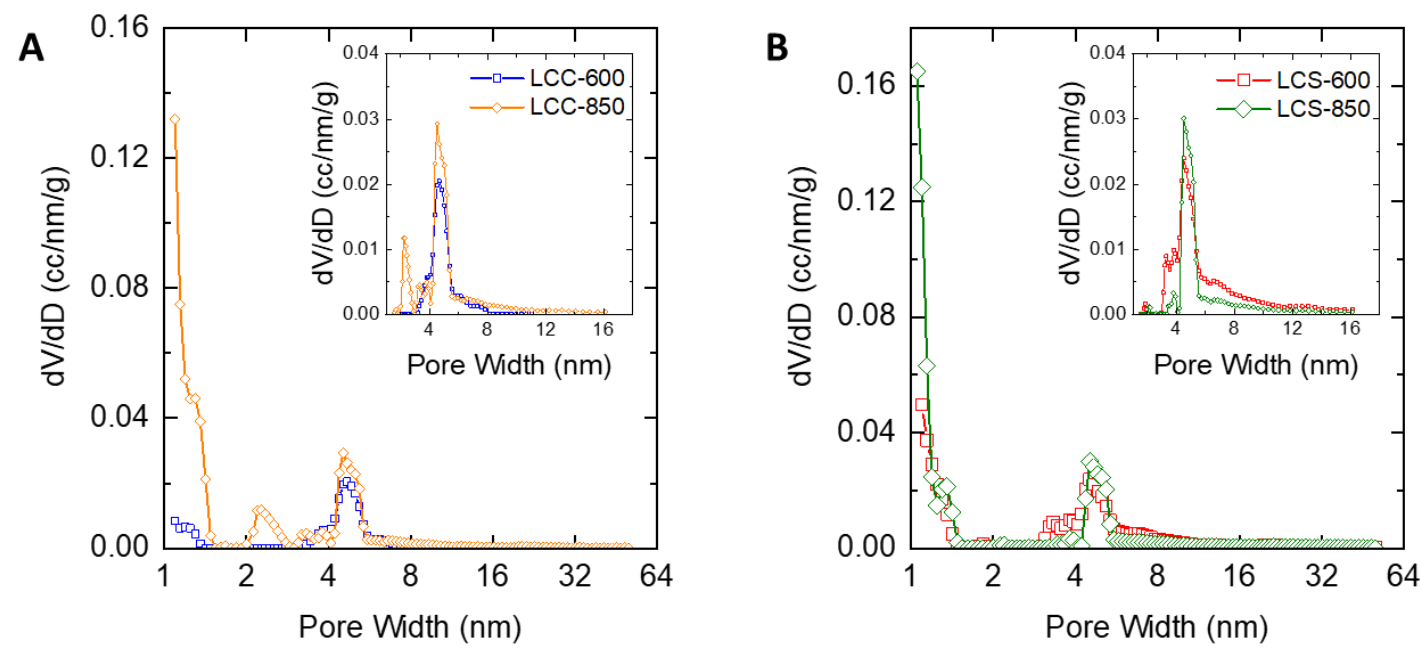

Figure 7. QSDFT-N 2 pore size distribution of carbon (A) corncob lignin; (B) coconut shell lignin.

The isotherm curves of nitrogen adsorption-desorption from Figures 5 and 6 were used for determining the pore structure. The calculation of specific surface area $\left(\mathrm{S}_{\mathrm{BET}}\right)$, mesopore specific surface area $\left(\mathrm{S}_{\text {meso }}\right)$, pore volume $(\mathrm{V})$, mesopore volume $\left(\mathrm{V}_{\text {meso }}\right)$ and average pore diameter $\left(\mathrm{D}_{\text {avg }}\right)$ for various precursor are shown in Table 3.

Table 3. Structural pore properties of carbon. Data of LMP-600 and LMP-850 taken from our previous study [18].

\begin{tabular}{|c|c|c|c|c|c|c|c|c|}
\hline Characteristics & $\mathrm{LMP}_{\mathrm{T}}-600$ & $\mathrm{LMP}_{\mathrm{T}}-850$ & LMP-600 & LMP-850 & LCC-600 & LCC-850 & LCS-600 & LCS-850 \\
\hline Mesopore area $\left(\mathrm{S}_{\text {meso }}\right), \mathrm{m}^{2} / \mathrm{g}$ & 110 & 153 & 85 & 42 & 28 & 59 & 58 & 50 \\
\hline Total pore volume, $\mathrm{cm}^{3} / \mathrm{g}$ & 0.37 & 0.55 & 0.21 & 0.28 & 0.16 & 0.38 & 0.21 & 0.35 \\
\hline Mesopore volume $\left(\mathrm{V}_{\text {meso }}\right), \mathrm{cm}^{3} / \mathrm{g}$ & 0.18 & 0.22 & 0.16 & 0.07 & 0.03 & 0.09 & 0.09 & 0.07 \\
\hline$\% \mathrm{~V}_{\text {meso }}$ & 48.4 & 40.21 & 72.40 & 23.8 & 17.03 & 22.61 & 45.27 & 20.64 \\
\hline
\end{tabular}

From Table 3, it is shown that LMPT-850 $\left(974 \mathrm{~m}^{2} / \mathrm{g}\right)$ possesses a higher specific surface area than the LMPT-600 $\left(567 \mathrm{~m}^{2} / \mathrm{g}\right)$ but both carbons are microporous carbons because of the low percentage of mesopore surface area $(<20 \%)$. The average diameter for LMPT-850 is $2.04 \mathrm{~nm}$, while LMPT-600 is 
$2.50 \mathrm{~nm}$. For LMP, the one carbonized at $600{ }^{\circ} \mathrm{C}$ features a high percentage of mesopore surface area $(41.76 \%)$ with an average pore diameter of $3.04 \mathrm{~nm}$, while that with a carbonization temperature of $850{ }^{\circ} \mathrm{C}$ shows a lower percentage of mesopore area (7.06\%) with an average pore diameter of $1.47 \mathrm{~nm}$. LMP-850 carbon is a micropore carbon, which gives a higher specific surface area $\left(595 \mathrm{~m}^{2} / \mathrm{g}\right)$ than LMP-600 carbon $\left(205 \mathrm{~m}^{2} / \mathrm{g}\right)$. All LCC and LCS carbons show similar carbon pore characteristics with a low percentage of mesopore surface area less than $20 \%$. Both LCC-850 $\left(820 \mathrm{~m}^{2} / \mathrm{g}\right)$ and LCS-850 $\left(781 \mathrm{~m}^{2} / \mathrm{g}\right)$ feature a higher specific surface area than LCC-600 $\left(349 \mathrm{~m}^{2} / \mathrm{g}\right)$ and LCS-600 $\left(333 \mathrm{~m}^{2} / \mathrm{g}\right)$ with average diameters in the range of 1.4-1.9 $\mathrm{nm}$.

In this work, porous carbon produced by carbonization of lignin had specific surface area in the range of 205-974 $\mathrm{m}^{2} / \mathrm{g}$ depending on lignin material and carbonization temperature. A higher temperature was favorable to obtain a high specific surface area. The highest specific surface area was $974 \mathrm{~m}^{2} / \mathrm{g}$, which can compete with commercially available porous carbon [36] and lignin-derived carbon as in the literature [37].

\section{Materials and Methods}

\subsection{Materials}

The biomass precursors used in this experiment were obtained from different places. Mangosteen peel, which had 180-355 $\mu \mathrm{m}$ particle size, was obtained from Bina Agro Mandiri, Bantul, D.I. Yogyakarta, Indonesia. The corncob was obtained from old pearl corn in Sripendowo Village, South Lampung, Indonesia. The coconut shell with dark brown color and size of 80 mesh was obtained from Ruko Taman Niaga, Semarang, Indonesia. The solvent for lignin extraction was ethanol (96\%, Sigma Aldrich, Singapore). Sulfuric acid (98\%, Sigma Aldrich, Singapore) was employed for lignin precipitation.

\subsection{Methods}

Extraction using the organosolv process at low temperature was carried out based on the method described in the literature [18,38]. Firstly, mangosteen peel was poured in ethanol $(60 \%)$ in a three-neck flask. The ratio of solid:liquid was set to $1: 8(w / v)$. The extraction process was carried out at $70{ }^{\circ} \mathrm{C}$ for $4 \mathrm{~h}$. After that, the black liquor obtained was separated from the solid phase using filtration. Precipitation of lignin was carried out by adding sulfuric acid $1 \mathrm{~N}$ until the $\mathrm{pH}$ was 2 . The lignin obtained was then taken from solution by centrifugation and dried in an oven overnight. Similar procedures of the organosolv process at low temperature were carried out for the corncob and coconut shell as raw materials of biomass. The lignin produced was labeled depending on the type of biomass i.e., LMP (lignin from mangosteen peel), LCC (lignin from corncob) and LCS (lignin from coconut shell). The extraction process at high temperatures was carried out in an autoclave reactor at a temperature of $150{ }^{\circ} \mathrm{C}$ and a pressure of 10 bar under nitrogen pressure. For extraction using the Soda process, a similar procedure was employed but the solvent was $10 \%$ sodium hydroxide (see the literature [18]). The properties of lignin were investigated by Fourier-transform infrared (FTIR) spectroscopy (Thermo Nicolet iS10 by Thermo Fisher Scientific, MA, USA) and lignin solution viscosity (DV-E Viscometer by Brookfield, Toronto, Canada).

Conversion of lignin to carbon was conducted by a carbonization process in a furnace at $600{ }^{\circ} \mathrm{C}$ and $850{ }^{\circ} \mathrm{C}$ under a flow of nitrogen. The detailed procedure is available elsewhere [38]. The carbon produced was labeled in accordance with the type of lignin after carbonization temperature. For instance, LMP-600 means porous carbon produced by pyrolysis of lignin from mangosteen peel at $600{ }^{\circ} \mathrm{C}$. The pore structure of carbon was characterized by $\mathrm{N}_{2}$-sorption analysis (NOVA 2000 by Quantachrome Instruments, Boynton Beach, FL, USA) and scanning electron microscopy, SEM (JSM 6510 LA by JEOL, Tokyo, Japan). 


\section{Conclusions}

Lignin was successfully extracted by the organosolv process. The yield of lignin depended on the types of biomass and extraction conditions. A higher extraction temperature was more favorable to obtain a greater amount of lignin. The FTIR spectra of lignin showed peaks of syringyl and guaiacyl units, which are typical features for a lignin standard. When lignin was converted to porous carbon, the temperature of pyrolysis significantly affected the yield and properties of the porous carbon produced. Pore structure analysis displayed that carbon from lignin of mangosteen peel, corncob, and coconut shell synthesized at $850{ }^{\circ} \mathrm{C}$ exhibited a high surface area of $>550 \mathrm{~m}^{2} / \mathrm{g}$. The highest surface area, up to $974 \mathrm{~m}^{2} / \mathrm{g}$, was obtained in this work. The results showed that lignin-derived carbon is promising and could be beneficial for porous carbon applications.

Author Contributions: Conceptualization, I.P. and R.R.; methodology, I.P., R.R., T.A.; investigation, P.R.P.; data curation, P.R.P.; writing - original draft preparation, I.P. and T.A.; writing—review and editing, I.P., R.R., W.-C.O. and T.A.; visualization, W.T.L.; supervision, I.P., T.A. and R.R.; funding acquisition, R.R. All authors have read and agreed to the published version of the manuscript.

Funding: This research was funded by World Class Research, Ministry of Research, Technology and Higher Education of the Republic of Indonesia, grant number 1987/UN1.DITLIT/DIT-LIT/LT/2019.

Conflicts of Interest: The authors declare no conflict of interest.

\section{References}

1. Prasetyo, I.; Mukti, N.I.F.; Ariyanto, T. Ethylene adsorption using cobalt oxide-loaded polymer-derived nanoporous carbon and its application to extend shelf life of fruit. Molecules 2019, 24, 1507. [CrossRef] [PubMed]

2. Aroua, M.K.; Daud, W.M.A.W.; Yin, C.Y.; Adinata, D. Adsorption capacities of carbon dioxide, oxygen, nitrogen and methane on carbon molecular basket derived from polyethyleneimine impregnation on microporous palm shell activated carbon. Sep. Purif. Technol. 2008, 62, 609-613. [CrossRef]

3. Prasetyo, I.; Mukti, N.I.F.; Fahrurrozi, M.; Ariyanto, T. Removing ethylene by adsorption using cobalt oxide-loaded nanoporous carbon. ASEAN J. Chem. Eng. 2018, 18, 9-16. [CrossRef]

4. Yeon, S.-H.; Osswald, S.; Gogotsi, Y.; Singer, J.P.; Simmons, J.M.; Fischer, J.E.; Lillo-Rodenas, M.A.; Linares-Solano, A. Enhanced methane storage of chemically and physically activated carbide-derived carbon. J. Power Sources 2009, 191, 560-567. [CrossRef]

5. Tee, E.; Tallo, I.; Kurig, H.; Thomberg, T.; Jänes, A.; Lust, E. Huge enhancement of energy storage capacity and power density of supercapacitors based on the carbon dioxide activated microporous SiC-CDC. Electrochimica Acta 2015, 161, 364-370. [CrossRef]

6. Gläsel, J.; Diao, J.; Feng, Z.; Hilgart, M.; Wolker, T.; Su, D.S.; Etzold, B.J. Mesoporous and graphitic carbide-derived carbons as selective and stable catalysts for the dehydrogenation reaction. Chem. Mater. 2015, 27, 5719-5725. [CrossRef]

7. Prasetyo, I.; Rochmadi, R.; Wahyono, E.; Ariyanto, T. controlling synthesis of polymer-derived carbon molecular sieve and its performance for $\mathrm{CO}_{2} / \mathrm{CH}_{4}$ separation. Eng. J. 2017, 21, 83-94. [CrossRef]

8. Petkovich, N.D.; Stein, A. Controlling macro- and mesostructures with hierarchical porosity through combined hard and soft templating. Chem. Soc. Rev. 2013, 42, 3721-3739. [CrossRef] [PubMed]

9. Presser, V.; Heon, M.; Gogotsi, Y. Carbide-derived carbons-from porous networks to nanotubes and graphene. Adv. Funct. Mater. 2011, 21, 810-833. [CrossRef]

10. Han, J.; Kwon, J.H.; Lee, J.-W.; Lee, J.H.; Roh, K.C. An effective approach to preparing partially graphitic activated carbon derived from structurally separated pitch pine biomass. Carbon 2017, 118, 431-437. [CrossRef]

11. Tagami, A.; Gioia, C.; Lauberts, M.; Budnyak, T.M.; Moriana, R.; Lindström, M.E.; Sevastyanova, O. Solvent fractionation of softwood and hardwood kraft lignins for more efficient uses: Compositional, structural, thermal, antioxidant and adsorption properties. Ind. Crop. Prod. 2019, 129, 123-134. [CrossRef]

12. Mohit, N.; Agarwal, B.; Porwal, A.; Yadav, B.; Dhannajay, K. Manufacturing of paper by sulphate (Kraft) process. Int. J. Sci. Res. Rev. 2014, 3, 106-120. 
13. Wang, F.-L.; Li, S.; Sun, Y.-X.; Han, H.-Y.; Zhang, B.-X.; Hu, B.; Gao, Y.-F.; Hu, X. Ionic liquids as efficient pretreatment solvents for lignocellulosic biomass. RSC Adv. 2017, 7, 47990-47998. [CrossRef]

14. Shiflett, M.B. Commercial Applications of Ionic Liquids. In Green Chemistry and Sustainable Technology; Springer International Publishing: Cham, Switzerland, 2020.

15. McDonough, T. The chemistry of organosolv delignification. IPST Tech. Pap. Ser. 1992, 455, 1-17.

16. ICIS. Indicative Chemical Prices A-Z. Available online: https://www.icis.com/explore/chemicals/channelinfo-chemicals-a-z/ (accessed on 2 July 2020).

17. Millati, R.; Wikandari, R.; Ariyanto, T.; Putri, R.U.; Taherzadeh, M.J. Pretreatment technologies for anaerobic digestion of lignocelluloses and toxic feedstocks. Bioresour. Technol. 2020, 304, 122998. [CrossRef]

18. Permatasari, P.R.; Prasetyo, I.; Ariyanto, T. Synthesis of nanoporous carbon from mangosteen peel lignin extracted by using organosolv and soda processes. In AIP Conference Proceedings; AIP Publishing: College Park, MD, USA, 2019; Volume 2085, p. 020051.

19. Marton, R.; Granzow, S. Ethanol-alkali pulping (Spruce chips, paper, pulp industry). J. Tech. Assoc. Pulp Pap. Ind. 1982, 65, 103-106.

20. Balogh, D.; Curvelo, A.; De Groote, R. Solvent effects on organosolv lignin from Pinus caribaea hondurensis. Holzforsch. 1992, 46, 343-348. [CrossRef]

21. Ni, Y.; Hu, Q. Alcell@lignin solubility in ethanol-water mixtures. J. Appl. Polym. Sci. 1995, 57, 1441-1446. [CrossRef]

22. Singh, S.K.; Dhepe, P.L. Isolation of lignin by organosolv process from different varieties of rice husk: Understanding their physical and chemical properties. Bioresour. Technol. 2016, 221, 310-317. [CrossRef] [PubMed]

23. Kline, L.M.; Hayes, D.G.; Womac, A.R.; Labbé, N. Simplified determination of lignin content in hard and soft woods via UV-spectrophotometric analysis of biomass dissolved in ionic liquids. BioResources 2010, 5, 1366-1383. [CrossRef]

24. Ramakoti, B.; Dhanagopal, H.; Deepa, K.; Rajesh, M.; Ramaswamy, S.; Tamilarasan, K. Solvent fractionation of organosolv lignin to improve lignin homogeneity: Structural characterization. Bioresour. Technol. Rep. 2019, 7, 100293. [CrossRef]

25. Wang, Y.; Liu, W.; Zhang, L.; Hou, Q. Characterization and comparison of lignin derived from corncob residues to better understand its potential applications. Int. J. Boil. Macromol. 2019, 134, 20-27. [CrossRef]

26. Zhang, X.; Yan, Q.; Leng, W.; Li, J.; Zhang, J.; Cai, Z.; Hassan, E.B. Carbon nanostructure of kraft lignin thermally treated at 500 to $1000{ }^{\circ} \mathrm{C}$. Materials 2017, 10, 975. [CrossRef] [PubMed]

27. Tolbert, A.; Akinosho, H.; Khunsupat, R.; Naskar, A.K.; Ragauskas, A.J. Perspective: Jatropha cultivation in southern India: Assessing farmers' experiences. Biofuels Bioprod. Biorefining 2012, 6, 246-256. [CrossRef]

28. Xue, B.-L.; Wen, J.-L.; Sun, S.-L. Producing lignin-based polyols through microwave-assisted liquefaction for rigid polyurethane foam production. Materials 2015, 8, 586-599. [CrossRef] [PubMed]

29. Mukti, N.I.F.; Prasetyo, I.; Mindaryani, A.; Septarini, S. Preparation of porous carbon as ethylene adsorbent by pyrolysis of extraction waste Mangosteen rinds. MATEC Web Conf. 2018, 154, 01032. [CrossRef]

30. Sych, N.; Trofymenko, S.; Poddubnaya, O.; Tsyba, M.; Sapsay, V.; Klymchuk, D.; Puziy, A.M. Porous structure and surface chemistry of phosphoric acid activated carbon from corncob. Appl. Surf. Sci. 2012, 261, 75-82. [CrossRef]

31. Ariyanto, T.; Sarwendah, R.A.G.; Amimmal, Y.M.N.; Laksmana, W.T.; Prasetyo, I. Modifying nanoporous carbon through hydrogen peroxide oxidation for removal of metronidazole antibiotics from simulated wastewater. Processes 2019, 7, 835. [CrossRef]

32. Thommes, M.; Kaneko, K.; Neimark, A.V.; Olivier, J.P.; Rodriguez-Reinoso, F.; Rouquerol, J.; Sing, K.S. Physisorption of gases, with special reference to the evaluation of surface area and pore size distribution (IUPAC Technical Report). Pure Appl. Chem. 2015, 87, 1051-1069. [CrossRef]

33. Do, D.D. Adsorption Analysis: Equilibria and Kinetics, 2nd ed.; Imperial College Press: London, UK, 1998; ISBN 1860941303.

34. Inagaki, M.; Tascón, J.D. Chapter 2 Pore formation and control in carbon materials. Interface Sci. Technol. 2006, 7, 49-105. [CrossRef]

35. Mestre, A.; Carvalho, A.P. Nanoporous Carbon Synthesis: An Old Story with Exciting New Chapters. In Porosity—Process, Technologies and Applications; IntechOpen: London, UK, 2018. 
36. Lee, C.; Ong, Y.; Aroua, M.K.; Daud, W. Impregnation of palm shell-based activated carbon with sterically hindered amines for CO2 adsorption. Chem. Eng. J. 2013, 219, 558-564. [CrossRef]

37. Sun, Y.; Yang, G.; Zhang, J.; Wang, Y.; Yao, M. Activated carbon preparation from lignin by $\mathrm{H}_{3} \mathrm{PO}_{4}$ activation and its application to gas separation. Chem. Eng. Technol. 2011, 35, 309-316. [CrossRef]

38. Permatasari, P.R. Pembuatan Karbon Berpori dari Lignin Hasil Ekstraksi Berbagai Limbah Biomass. Master's Thesis, Universitas Gadjah Mada, Yogyakarta, Indonesia, 2019.

Sample Availability: Samples of the compounds of lignin-derived carbons are available from the authors.

(C) 2020 by the authors. Licensee MDPI, Basel, Switzerland. This article is an open access article distributed under the terms and conditions of the Creative Commons Attribution (CC BY) license (http://creativecommons.org/licenses/by/4.0/). 